\title{
Effects of hypercapnic-hypoxic training on respiratory muscle strength and front crawl stroke performance among elite swimmers
}

\author{
Dajana KARAULA ${ }^{1}$, Jan HOMOLAK ${ }^{2}$, Goran LEKO ${ }^{1}$ \\ ${ }^{1}$ Department of Sport, Faculty of Kinesiology, University of Zagreb, Croatia \\ ${ }^{2}$ School of Medicine, University of Zagreb, Croatia \\ Address Correspondence to D. Karaula, e-mail: dajana.zoretic@kif.hr
}

\begin{abstract}
The aim of this resent study was to determine the effects of an 8-week hypercapnic-hypoxic ( $\mathrm{H}-\mathrm{H}$ or apnea) training program on respiratory muscles strength and 100 meter crawl swimming performance. The study was conducted on a sample of 26 Croatian elite swimmers (experimental group [EG] $n=12$, control group [CG] $n=14$ ). Both groups were subjected to the same swimming training programs and training sessions on a treadmill. The experimental group was additionally subjected to hypercapnic-hypoxic training program with increased muscular activity. Date on the following outcome variables were collected: the strength of respiratory muscles (maximal inspiratory pressure (MIP) and maximal expiratory pressure (MEP)), $100 \mathrm{~m}$ front crawl swimming time $(\mathrm{R} 100 \mathrm{~m})$ and breathing frequency during the same test $\left(\mathrm{BF}_{100 \mathrm{~m}}\right)$. A series of two way repeated measures ANOVAs has shown significant interactions between group (EG and CG) and the repeated-measure factor (pre- and post-test) (MIP: $p=0.006$, MEP: $p<0.001$, R100m, $p<0.001$, FB100m, $p<0.001$ ), all showing greater efficacy of the experimental program. It seems that the hypercapnic-hypoxic training program may provide substantial benefits for elite swimmers, in addition to their standard training sessions.
\end{abstract}

Keywords: Breathing frequency, expiratory muscles strength, hypercapnic-hypoxic training, inspiratory muscles strength, 100 $\mathrm{m}$ front crawl stroke.

\section{INTRODUCTION}

Breathing during swimming may interfere with propulsion and cause disruptions in timing between two strokes $(24,37)$. To avoid that, elite swimmers, especially on shorter distances, often endeavor to reduce their breathing frequency during swimming as much as possible. This means that they take a breath every third or fourth, or even fifth or sixth stroke. Such breathing rhythm enables them to swim mechanically more effectively $(24,31)$ and therefore faster $(5,31)$. Due to the occurrence of hypercapnia, respiratory and metabolic acidosis, reduced breathing frequency may lead to earlier occurrence of fatigue $(16,44,45,48)$. Increases in arterial $\mathrm{PCO}_{2}$ stimulate breathing through both, the carotid bodies and the central chemoreceptors. This lead to the assumption that hypercapnic training could increase swimmers' ability to hold their breath longer during the race by postponing the stimulus to breathing, and consequently allow for more efficient technique and faster swimming (20).
Research on breath-hold divers who had hypercapnic trainings outside the water (walking apnea) has shown that the spleen contraction, reduction in blood acidosis, and oxidative stress occur during the voluntary breath holding (apnea) $(9,16)$. Some previous studies have discovered presence of a weakened ventilation response in breath-hold divers and synchronized swimmers $(2,4,10,33)$. However, the hypothesis that exposure to hypercapnic condition reduces the ventilation response to increased $\mathrm{CO}_{2}$ concentrations was rejected.

Different methods of restricting lung ventilation are used as part of swimming training. For example, a common practice is swimming with reduced breathing frequency and enlarged dead space by using a snorkel. Hypercapnic-hypoxic $(\mathrm{H}-$ $\mathrm{H}$ or apnea) training outside water with increased muscular stress seems to be a less common practice. It was shown that training of breath holding may improve tolerance to hypoxemia, regardless of the genetic factor or buffering muscle capacity (19). 
Other studies have indicated that this may then positively influence anaerobic and/or anaerobic capacity $(22,47)$. Accordingly, a recent study has shown positive effects of hypercapnic-hypoxic training on hemoglobin concentrations and maximum oxygen uptake among elite swimmers (49). Several researchers tried to take the advantage of physiological adaptations associated with hypercapnia and hypoxia. The most common way to induce hypercapnia and hypoxia described in literature is hypoventilation and reduced breathing frequency $(\mathrm{RBF})$. Since there is a great resemblance between RBF training and $\mathrm{H}-\mathrm{H}$ training, we believe that some of the training effects that have been repeatedly reported with $\mathrm{RBF}$ can also be accomplished with $\mathrm{H}-\mathrm{H}$ training. $\mathrm{RBF}$ training can be done either at low or high lung volumes with $\mathrm{RBF}$ at high lung volume being more similar to $\mathrm{H}-\mathrm{H}$ training. Studies indicate that RBF training at high lung volumes can increase tidal volume during incremental exercise and decrease the ventilatory response to exercise induced hypercapnia $(14,18,20)$. Moreover, Kapus et al. also reported the effects of RBF training in swimmers. Swimmers in the experimental group showed higher lactate concentrations and greater $\mathrm{PCO}_{2}$ after the training. Because of the long lasting stimulus, swimmers adapted to swimming with fewer breaths (19).

According to Sharp et al. $(38,39)$, the greater respiratory muscle strength is a factor which contributes to a positive relation between the strength of the torso and the swimming performance. Moreover, Kilding et al. (21) have demonstrated that inspiratory muscle training can improve swimming performance in club-level trained swimmers in events shorter than $400 \mathrm{~m} \mathrm{(21).}$ It could be assumed that increased strength of respiratory muscles may positively affect swimming performance through increased volume of air exchanged within each inhalation and exhalation, and consequently reduced breathing frequency during the race. Greater amount of air in the lungs may also have positive effect on the buoyancy of swimmers. Evidence about the effects of respiratory muscle strength on breathing frequency during swimming and swimming performance is scarce. Furthermore, no previous studies have examined the effects of hypercapnic-hypoxic training on muscle-strength of elite swimmers.

\section{MATERIALS \& METHOD}

\section{Participants}

The study included a sample of 26 elite male swimmers (age range 17 to 25 years). All participants trained regularly for eight or more consecutive years, with a minimal training load of 1 two-hour session six days a week. Stratified randomization was applied to form the experimental (EG; $\mathrm{n}=12$ ) and control group (CG; $\mathrm{n}=14$ ), where the prior stratification of the sample was done according to the International Point Scores (IPS) for $100 \mathrm{~m}$ front crawl stroke.

Based on the medical examination, all participants obtained physician consents for participating in competitive swimming events. All participants signed a written informed consent, before taking part in the study.

\section{Experimental procedures}

Data was collected on two occasions (pre und post), eight weeks apart, using standardized procedures. The maximal strength of inspiratory muscles (MIP) and maximal strength of expiratory muscles (MEP) were assessed via the respiratory pressure meter MicroRPM ${ }^{\mathrm{TM}}$ Software (Puma PC, Micro Medical, Kent, England). The 100m front crawl stroke swimming performance times were measured in a short-course $(25 \mathrm{~m})$ swimming pool by Omega OCP5 touchpad. During the same test, the breathing frequency $\left(\mathrm{BF}_{100 \mathrm{~m}}\right)$ was assessed on the $100 \mathrm{~m}$ front crawl stroke swimming performance.

Between the baseline and follow up measurements, both EG and CG engaged in their standard training programs, including swimming and treadmill sessions. Additionally, the EG underwent hypercapnic-hypoxic $(\mathrm{H}-\mathrm{H})$ training sessions on a treadmill 3 times a week for 8 weeks. Each $\mathrm{H}-\mathrm{H}$ session was approximately 30-45 minutes long. The heart rate $\left(\mathrm{HR}_{\max }\right)$ at the maximum oxygen uptake $\left(\mathrm{VO}_{2 \max }\right)$ was used to determine the treadmill speed. The treadmill speed remained the same during the whole training program. Oxygen blood saturation $\left(\mathrm{SaO}_{2}\right)$, the carbon dioxide amount in the exhaled breath $\left(\mathrm{CO}_{2}\right)$ and the heart rate $(\mathrm{HR})$, which was $60 \%$ from the maximum $\mathrm{HR}$, were constantly monitored. Each test subject was instructed to hold his breath for as long as possible. Hypercapnia was monitored with capnometer (Model C300, External Sidestream ETCO2 Module, Beijing National Medical Co) and oxygen saturation was controlled with Edan H100B oximeter (Edan Instruments, 
China). Targeted values for blood gas carbon dioxide levels were over $45 \mathrm{mmHg}$ which is the laboratory diagnostic criteria for hypercapnia. Breath-holding time necessary to induce hypercapnia was determined for each test subject. . The breaks between two breath-holding cycles were defined as one full ventilation cycle (inhalation, holding the breath + exhalation, inhalation exhalation, inhalation + holding the breath).

In addition to regular swimming training sessions, the control group underwent aerobic training on a treadmill at $60 \%$ of the maximal heart rate 3 times a week for 8 weeks. Each training session was approximately 30-45 minutes long.

\section{Statistical analysis}

Means and standard deviations were calculated for each dependent variable. One-simple the D'Agostino-Pearson test, Histogram test, Probability-probability plot (P-P plot) and Kolmogorov-Smirnov test confirmed normal distributions (13). Maximal strength of inspiratory muscles (MIP) and maximal strength of expiratory muscles (MEP), breathing frequency on $100 \mathrm{~m}$ front crawl stroke $\left(\mathrm{BF}_{100 \mathrm{~m}}\right)$ and results on $100 \mathrm{~m}$ front crawl stroke $(\mathrm{R} 100 \mathrm{~m})$ were compared using a oneway ANOVA with repeated measures. An alpha value of $p<0.05$ was assumed to check statistical significance. The effect size of the obtained hypercapnic-hypoxic training differences in the dimension of the initial and final measurements in all parameters was calculated with the Cohen dindex. The data were analyzed using that statistical software Statistica (ver.11.0).

\section{RESULTS}

The mean, standard deviation and Cohen $\mathrm{d}$ for both group in initial and final measurement are summarized in Table 1. Based on the numerical parameters (Table 2) of the t-test for independent specimens through $p$-values $(p<0.05)$ it is noticeable that there is no statistically significant difference of all variables in the initial measurement between the experimental and the control group.

The results of a series of ANOVA for the repeated measurements show that there were statistically significant difference in maximal strength of inspiratory muscles, maximal strength of expiratory muscles, breathing frequency on $100 \mathrm{~m}$ front crawl stroke and results on $100 \mathrm{~m}$ front crawl stroke. The differences are shown separately for each variable in Figures 1, 2, 3 and 4.

Figure 1 shows the results of the results on 100 $\mathrm{m}$ front crawl stroke (R100m). As shown, the EG and the $C G$ are homogenous in the initial state $(p=.626)$. In the final measurement the swimmers who were subjected to the hypercapnic-hypoxic training program scored better than the swimmers who were not subjected to the program. Based on the results on $100 \mathrm{~m}$ front crawl stroke in the initial measurement $(\mathrm{R} 100 \mathrm{~m})(56.75 \pm 2.09)$ and in the final measurement $(54.72 \pm 2.75)$ it can be concluded that the R100 has decreased for $3.6 \%$. Control group improved result for $1.1 \%$.

Figure 2 shows the results in the breathing frequency on $100 \mathrm{~m}$ front crawl stroke $\left(\mathrm{BF}_{100 \mathrm{~m}}\right)$. EG swimmer reduced the $\mathrm{BF}_{100 \mathrm{~m}}$ and Cohen $\mathrm{d}$ shown the large effect (Cohen $\mathrm{d}=1.83$ ).

Figure 3 shows the results of maximal strength of inspiratory muscles and Figure 4 shows the results of maximal strength of expiratory muscles. In the final measurement the swimmers who were subjected to the hypercapnic-hypoxic training program scored better than the swimmers who were not subjected to the program. During the training period the MIP at EG increased for $14.9 \%$ and MEP for $1.9 \%$.

Table 1. Results of descriptive statistics for the experimental and control group in initial and final measurement.

\begin{tabular}{|c|c|c|c|c|c|c|}
\hline Variable & $\begin{array}{c}\text { Experimental group - } \\
\text { Initial measurement }\end{array}$ & $\begin{array}{c}\text { Experimental group - } \\
\text { Final measurement }\end{array}$ & $\begin{array}{c}\text { Cohen } \\
\text { d }\end{array}$ & $\begin{array}{c}\text { Control group - Initial } \\
\text { measurement }\end{array}$ & $\begin{array}{c}\text { Control group - } \\
\text { Final measurement }\end{array}$ & $\begin{array}{c}\text { Cohen } \\
\text { d }\end{array}$ \\
\hline & Mean. \pm SD & Mean \pm SD & & Mean \pm SD & Mean \pm SD & \\
\hline MIP & $119.86 \pm 19.33$ & $146.21 \pm 31.32$ & 1.07 & $126.42 \pm 27.72$ & $124.50 \pm 29.78$ & 0.07 \\
\hline MEP & $130.36 \pm 27.78$ & $149.71 \pm 30.82$ & 0.69 & $153.25 \pm 36.59$ & $146.92 \pm 30.80$ & 0.20 \\
\hline $\mathrm{BF}_{100 \mathrm{~m}}$ & $19.83 \pm 2.52$ & $16.08 \pm 1.68$ & 1.83 & $20.36 \pm 2.65$ & $18.79 \pm 1.93$ & 0.70 \\
\hline R100m & $56.75 \pm 2.09$ & $54.72 \pm 2.75$ & 0.86 & $56.30 \pm 2.52$ & $55.70 \pm 2.34$ & 0.26 \\
\hline
\end{tabular}

Legend: Mean - mean, SD - standard deviation, Cohen d- effect size used to indicate the standardized diffrence between txo means, an effect size is a measure of the strength of a phenomenon, MIP - maximal strength of inspiratory muscles, MEP - maximal strength of expiratory muscles, BF100m breathing frequency on $100 \mathrm{~m}$ front crawl stroke, R100m - results on $100 \mathrm{~m}$ front crawl stroke 
Table 2. Results of t-test for independent samples in the initial measurement.

\begin{tabular}{lccc}
\hline \multirow{2}{*}{ Variable } & Experimental group - Initial measurement & Control group - Initial measurement & \multirow{2}{*}{$\mathrm{p}$} \\
\cline { 2 - 3 } & Mean \pm SD & Mean \pm SD & 0.486 \\
MIP & $119.86 \pm 19.33$ & $126.42 \pm 27.72$ & 0.082 \\
MEP & $130.36 \pm 27.78$ & $153.25 \pm 36.59$ & 0.611 \\
BF100m & $19.83 \pm 2.52$ & $20.36 \pm 2.53$ & 0.626 \\
R100m & $56.75 \pm 2.09$ & $56.30 \pm 2.52$ & \\
\hline
\end{tabular}

Legend: Mean - mean, SD - standard deviation, $\mathbf{p}$ - statistically significant at level $\mathrm{p}<05$, MIP - maximal strength of inspiratory muscles, MEP - maximal strength of expiratory muscles, BF100m - breathing frequency on $100 \mathrm{~m}$ front crawl stroke, R100m - results on $100 \mathrm{~m}$ front crawl stroke.

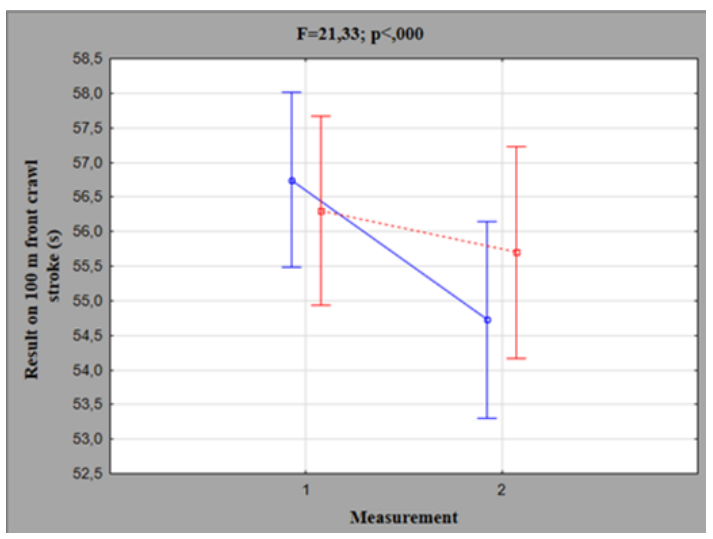

Figure 1. The diference between the experimental and control group in the initial and final measurement in the variable of result on $100 \mathrm{~m}$ front crawl stroke.

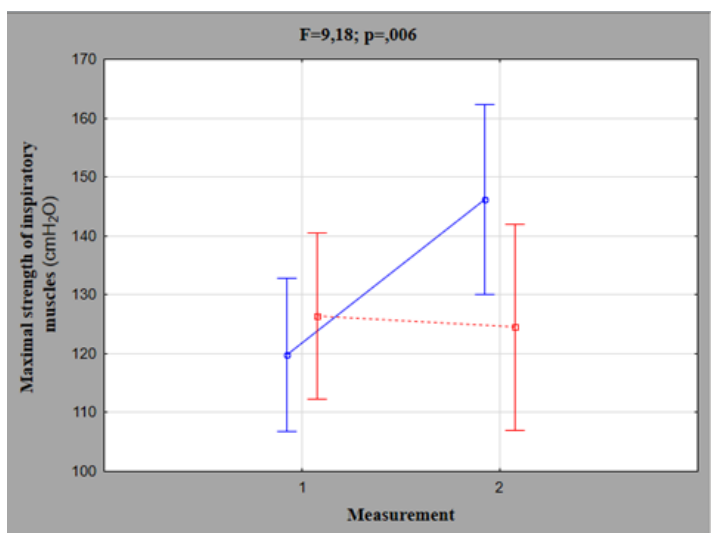

Figure 3. The diference between the experimental and control group in the initial and final measurement in the variable of maximal strength of inspiratory muscles.

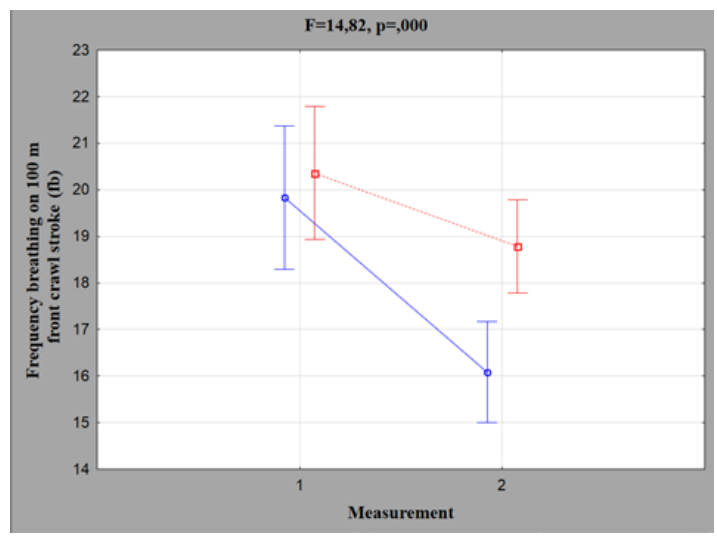

Figure 2. The diference between the experimental and control group in the initial and final measurement in the variable of breathing frequency on $100 \mathrm{~m}$ front crawl stroke.

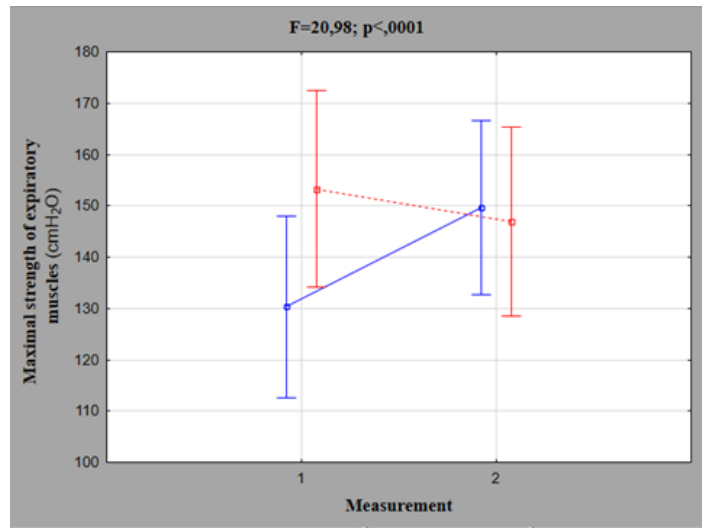

Figure 4. The diference between the experimental and control group in the initial and final measurement in the variable of maximal strength of expiratory muscles.

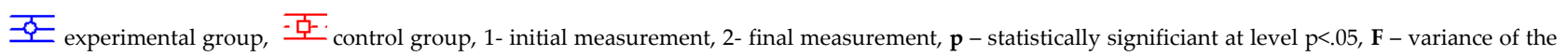
group means / mean of the within group variances.

\section{DISCUSSION}

Since pulmonary system can limit maximal exercise performance $(1,3,7)$ and accessory respiratory muscles greatly contribute to functioning of the respiratory system during maximal sport performance, their role in performance and potential benefit of respiratory training implementation in exercise program should be considered. Fatigue of the respiratory musculature is important factor that can limit sport performance and eventually even cause cessation of sport activity. Several studies have reported potential benefit of respiratory muscle training in various sports. Respiratory muscle training improves recovery time during high intensity, intermittent exercise in repetitive sprint athletes (34), anaerobic capacity in cyclists (15) and rowing performance (12). Theoretical benefit of 
increased inspiratory and expiratory muscle strength we observed could be huge.

The increased strength of inspiratory and expiratory muscles of swimmers in the EG could have resulted in the enlarged volume of air exchanged with each breath. Thus, the content of dead space in breath $(150 \mathrm{~mL})$ was perceptually reduced. A larger amount of air in lungs has a positive effect on the amount of the available oxygen, elimination of excess $\mathrm{CO}_{2}$ and flotation of swimmers. Mentioned factors could have caused observed reduction in number of breaths as well as improvement in result in 100-meter front crawl race (19). Breathing during swimming interferes with the swimming technique quality and causes a time disbalance between two strokes $(24,37)$. Therefore, swimmers are advised to swim with as few inhalations as possible when swimming shorter distances. The time spent on every inhalation is 0.2 seconds on average (26).

In the context of competitive swimming, measuring of respiratory muscle strength has not been widely analyzed. The swiftness of exhalation during swimming and the additionally increased hydrostatic pressure to the thorax can result in pressure to the chest wall towards inside when the inspiratory muscles are relaxed and weak (6). When muscles are relaxed, water pressure presses the lung wall from the outside and antagonizes respiratory muscles during inhalation (11), which results in a pronounced exhalation in water and larger stress during inhalation. The somewhat difficult functioning of the respiratory muscles results in arterial vasoconstriction which is the consequence of the reduced concentration of $\mathrm{CO}_{2}$ caused by hyperventilation (42).

It must be pointed out that all the tested swimmers have been practicing for twelve years on average. Since this analysis includes top swimmers, the large homogeneity in obtained respiratory muscle function measures is understandable. In course of their long-time practice the swimmers have become familiar with the fact that the increased breathing frequency and irregular breathing in water causes the time disbalans between two strokes, which renders achievement of the desired result impossible. Years of repetitive hypercapnic episodes during swimming training caused adaptations to higher quantities of $\mathrm{CO}_{2}$ by reducing chemo-receptor sensitivity. Improvement in 100 front crawl swimming result can also be partially explained by change in breathing pattern frequency seen in experimental group subjects during final 100 front crawl swim. Figure 3 and 4 shows that the group of swimmers, who were subjected to the hypercapnic-hypoxic regimen, has significantly improved strength of their inspiratory and expiratory muscles in comparison to swimmers in the control group. The swimmers from the experimental group have improved the inspiratory muscle strength values (MIP) for $14.9 \%$ and the expiratory muscle strength values (MEP) for $1.9 \%$ in relation to the control group. There is a statistically significant difference between the performance values of the experimental group (Table 1).Based on the previously conducted analyses $(1,25,22,35)$ it can be concluded that the Croatian swimmers have similar values of initially measured respiratory muscle strength in relation to swimmers and free divers mentioned in these analyses.

Based on the results of this study it can be assumed that the hypercapnic-hypoxic practice has significantly increased the respiratory muscle strength. Statistically significant differences can be attributed to the eight-week exposure to hypercapnia and hypoxia combined with increased muscle activity. Such practice must have enlarged the diaphragm thickness which plays an important role in respiratory system and sports performance (8). Voluntary holding of breath may have resulted in involuntary contractions of intercostal muscles during the hypercapnic-hypoxic practice. It is also assumed that above mentioned contraction occurrence has resulted in hypertrophy of intercostal muscles. According to the available literature, mobility of breastbone and costal joints and changes in lung and breast muscle elasticity (30) are also possible changes that occur during voluntary breath holding. Maximum inspiratory pressure is of great importance in swimming due to the limited inhalation time - the stronger the inspiratory muscles, the more air can be inhaled into the lungs in a shorter period of time.

Athletes with lower MIP values are more sensitive to fatigue during practice $(27,28,29)$. Literature also suggests that escalation of MIP values correlates with greater lung diffusion capacity. Because of the increase in respiratory muscle strength, the critical swimming speed (41) and the swimming durability (49) were improved. It should be noted that the change in relative diaphragm contributions (movement of abdominal cavity) in relation to the movements of the thorax and contractions of intercostal muscles in relation to 
the respiratory volume are of great importance. The diaphragm prevails in stand-still condition and during the chemical breathing stimulation, while the intercostal muscles prevail during the intense practice.

Sprinters who have specialized for 100-meter races should be subjected to certain hypercapnichypoxic workouts and often do sprint racing without breathing (26). To swim a 100-meter race, distance swimmers must have highly developed anaerobic metabolic system strength. Endurance training increases the efficiency of aerobic metabolism by increasing quantity of myoglobin and hemoglobin concentration and thus enabling more oxygen to be transported into muscle cells (26).

A 100-meter front crawl stroke distance takes 50 to 60 seconds. Energy needs are covered by: ATP-KP with $10 \%$, anaerobic glycolysis system with $55 \%$ and aerobic metabolism with 35\% (26). Since the group of swimmers who were subjected to hypercapnichypoxic practice have developed statistically significant differences such as: higher hemoglobin concentration and maximum oxygen uptake (50) as well as respiratory muscle strength, it can be assumed that observed improvement in swimming performance can mainly be attributed to aerobic energy system adaptations. The increase of oxygen supply to the muscles enables metabolizing larger quantities of pyruvate and hydrogen ions delaying occurrence of acidosis and thus allowing swimmers to swim faster. It can be assumed that buffering capacities are improved, which then in turn influences the acid-base balance (local level/cellular) and buffer capacities of hemoglobin (general level/extracellular) as well as the lactate transporter MCT4 (40). Some other researched also suggest that such type of (interrupted) hypoventilation practice influences arterial desaturation, induces hypercapnia and thus encourages development of higher buffering capacities $(43,44,46,47)$.

Aforementioned adaptations allow swimmer to prolong usage of energy sources needed for extreme requirements during race. Activation of anaerobic glycolysis occurred in top swimmers subjected to hyprecapnic-hypoxic practice, most probably due to better buffering which enables a more efficient energy production and thus a longer anaerobe glycolysis period. Based on the increased hemoglobin concentration (50), swimmers who were subjected to hypercapnic-hypoxic practice may also have increased their aerobic capacity, ability to

Turk ل Spart Exe 2016; I8(I): 17-24

[ 2016 Faculty of Sport Sciences, Selcuk University recuperate faster and endure longer and more intense workouts.

Besides the stated assumptions, swimmers who were subjected to hypercapnic-hypoxic practice had lesser number of inhalations than the control group (Figure 2). One of the reasons may be the increased respiratory muscle strength which contributes to a positive relation between the torso and the swimming performance $(38,39)$ and enables swimmer to (can) inhale more air in one inhalation. The second reason could be the chemoreceptors have become less sensitive to increased levels of $\mathrm{CO}_{2}$ in blood due to the hypercapnic-hypoxic practice.

The result analysis (Figure 1) of a 100-meter front crawl distance (R100m) has established a statistically significant difference in progress between the experimental and the control group. Both groups of swimmers have obtained better results in final measurements, which can be explained by training program both groups took part in. The experimental group has improved its result for $3.6 \%$ compared to the initial measurement and the control group improved its result for $1.1 \%$.

The difference in progress can be attributed to positive influence of hypercapnic-hypoxic training on swimmers' buffering capacity. Hypercapnichypoxic training also causes spleen contraction, which improves oxygen transmission due to increase in number of erythrocytes and hemoglobin concentration $(17,23,32,36)$.

According to obtained results it can be assumed that the hypercapnic-hypoxic practice has resulted in stretching of all muscles surrounding the thorax and thus increasing the total lung capacity and respiratory muscle strength. Muscles which surround the thorax are one of two primary generators of force which shoves the swimmer through the water. Based on the obtained results it can be assumed that top swimmers who have been subjected to the hypercapnic-hypoxic practice developed better buffering capacity due to stronger respiratory muscles and increase in hemoglobin concentration. Also, better tolerance to the increased level of $\mathrm{CO}_{2}$ in blood has been observed due to decrease in chemoreceptor sensitivity.

Understanding the adjustment to normobaric hypercapnia and hypoxia is of great importance in kinesiology and sport physiology. Better understanding of mechanisms behind physiological adaptation to hypercapnia and hypoxia such as changes in buffering capacity, metabolic and 
hematological adaptations can immensely influence theoretical sport science.

\section{REFERENCES:}

1. Amann, Markus. Pulmonary system limitations to endurance exercise performance in humans. Exp Physiol, 2012, 97(3):311-18.

2. Bakovic D, Valic Z, Eterovic D, Vukovic I, Obad A, Marinovic-Terzic I, Dujic, Z. Spleen volume and blood flow response to repeated breathhold apneas. J Appl Physiol, 2003, 95:1460-6

3. Boutellier U, Büchel R, Kundert A, Spengler C. The respiratory system as an exercise limiting factor in normal trained subjects. Eur J Appl Physiol Occup Physiol, 1992; 65(4):347-53.

4. Breskovic T, Ivancev V, Banic I, Jordan, J, Dujic, Z. Peripheral chemoreflex sensitivity and sympathetic nerve activity are normal in apnea divers during training season. AUTON NEUROSCI-BASIC, 2010; 19:154(1-2):42-7.

5. Castro F, Guimaraes AC. Front crawl kinematic: breathing and pace acute effect. Portugese Journal of Sport Science, 2006; 6 (2); 26-28.

6. Cordain L, Stager J. Pulmonary structure and function in swimmers. Sports Med, 1998; 6:271-278.

7. Dempsey J, Hanson P, Pegelow D, Claremont A, and Rankin J. Limitations to exercise capacity and endurance: pulmonary system. Can J Appl Sport Sci. Journal canadien des sciences appliquées au sport, 1982; 7(1):4-13.

8. Enright S, Heward C, Withnall L, Davies DH, Unnithan VB. Inspiratory muscle training improves lung function and exercise capacity in healthy subjects. Phy Ther; 2006; 86(3):345-354

9. Espersen $\mathrm{K}$, Frandsen $\mathrm{H}$, Lorentzen $\mathrm{T}$, Kanstrup $\mathrm{IL}$, Christensen NJ. The human spleen as an erythrocyte reservoir in diving-related interventions. J Appl Physiol, 2002; 92(5):2071-9.

10. Florio JT, Morrison JB, Butt WS. Breathing pattern and ventilatory response to carbon dioxide in divers. J Appl Physiol, 1979; 46:1076-80

11. Frangolias D, Rhodes E. (1996). Metabolic responses and mechanisms during water immersion running exercise. Sports Med, 1996; 22(1): 38-53.

12. Griffiths LA, McConnell AK. The influence of inspiratory and expiratory muscle training upon rowing performance. Eur J Appl Physiol, 2007; 99(5):457-66

13. Hopkins KD, Weeks DL. Tests for normality and measures of skewness and kurtosis: Their place in research reporting. Educ Psychol Meas, 1990; 50:717-729.

14. Jakovljevic DG, McConnell AK. Influence of different breathing frequencies on the severity of inspiratory muscle fatigue induced by high-intensity front crawl swimming. J Strength Cond Res, 2009; 23, 1169-1174.

15. Johnson MA, Graham R. Sharpe GR, Brown PI. Inspiratory muscle training improves cycling time-trial performance and anaerobic work capacity but not critical power.. Eur J Appl Physiol, 2007; 101(6):761-70.
16. Joulia F, Steinberg JG, Faucher M, Jamin T, Ulmer C, Kipson $\mathrm{N}$, Jammes $\mathrm{Y}$. Breath-hold training of humans reduces oxidative stress and bloodacidosis after static and dynamic apnea. Resp Physiol Neurobi, 2003; 137: 19-27.

17. Joulia F, Steinberg JG, Wolff F, Gavarry O, Jammes Y. Reduced oxidative stress and blood lactic acidosis in trained breath-hold human divers. Resp Physiol Neurobi 2002; 133: 121-130.

18. Kapus J, Kapus V, Štrumbelj B. Ušaj A.Can high intensity workloads be simulated at moderate intensities by reduced breathing frequency? Biol Sport, 2010a; 27, 163-168.

19. Kapus J, Ušaj A, Kapus V, Štrumbelj B. The influence of training with reduced breathing frequency in front crawl swimming during a maximal 200 meters front crawl performance. Kinesiologia Slovenica, 2005; 11, 17-24.

20. Kapus J, Ušaj A, Lomax M. Adaptation of endurance training with a reduced breathing frequency. J Sports Sci Med, 2013;12 (4), 744-752.

21. Kilding AE, Brown $\mathrm{S}$, McConnell AK. Inspiratory muscle training improves 100 and $200 \mathrm{~m}$ swimming performance. Eur J Appl Physiol; 2010; 108(3):505-11.

22. Klusiewicz,A. Characteristics of the inspiratory muscle strength in the well-trained male and female athletes. Biol Sport, 2008; 25:13-22.

23. Lemaîtrea F, Joulia F, Chollet D. Apnea: A new training method in sport? Med Hypotheses, 2010; 74; 413-415.

24. Lerda R, Cardelli C, Chollet D. Analysis of the interactions between breathing and arm actions in the front crawl. J Hum Mov Stud, 2001; 40: 129-144.

25. Lindholm P, Wylegala J, Pendergast DR, Lundgren CE. Resistive respiratory muscle training improves and maintains endurance swimming performance in divers. Undersea Hyperbar M 2007; 34(3):169-80

26. Maglischo EM. Swimming fastest. The esential reference on technique, training and program design. Human Kinetics. Champaing, IL, 2003; 445-446.

27. McConnell AK, Caine MP, Sharpe GR. Inspiratory muscle fatigue following running to volitional fatigue: The influence of baseline strength. Int J Sports Med, 1997; 18:169-173.

28. McConnell AK, Lomax M. The influence of inspiratory muscle work history and specific inspiratory muscle training upon human limb muscle fatigue. J Appl Physiol, 2006; $577: 445-457$

29. McConnell AK, Romer LM. Respiratory muscle training in healthy humans: resolving the controversy. Int J Sports Med, 2004; 25:284-293.

30. Meenakshi S, Vaidya SM, Sable SS. Comparative study of lung functions in swimmersand runners. Indian J Physiol Pharmacol, 2012; 56(1):100-104

31. Pedersen T, Kjendlie PL. The effect of the breathing action on velocity in front crawl sprinting. Revista Portuguesa de Ciências do Desporto, 2006; 6(2) 75-78.

32. Prommer N, Ehrmann U, Schmidt W, Steinacker JM, Radermacher P, Muth CM. Total haemoglobin mass and spleen contraction: a study on competitive apnea divers, nondiving athletes and untrained control subjects. Eur J Appl Physiol, 2007; 101: 753-759. 
33. Rodriguez-Zamora L, Iglesias X, Barrero A, Chaverri D, Erola $\mathrm{P}$, Rodriguez F. Physiological responses in relation to performance during competition in elite synchronized swimmers, 2012; PLoS One 7 (11): e49098.

34. Romer LE, McConnell AK, Jones DA. Inspiratory muscle fatigue in trained cyclists: effects of inspiratory muscle training. Med Sci Sports Exerc, 2002; 34(5): 785-792.

35. Santos MA, Pinto ML, SantAnna CC, Bernhoeft M. Maximal respiratory pressures among adolescent swimmers. Rev Port Pneumol, 2011; 17(2): 66-70.

36. Schagatay E, Haughey H, Reimers J. Speed of spleen volume changes evoked by serial apneas. Eur J Appl Physiol, 2005; 93: 447-452.

37. Seifert L, Chollet D, Chatard JC. Kinematic changes during a 100-m front crawl: effects of performance level and gender. Med Sci Sports Exerc, 2007;1784 -1793.

38. Sharp R, Troup JP, Costill DL. Relationship between power output and sprint freestyle swimming. Med Sci Sports Exerc, $1982 ; 14,53-6$

39. Sharp RL, Williams DJ, Bevan, L. Effects of controlled frequency breathing during exercise on blood gases and acidbase balance. Int J Sports Med, 1991; 12, 62-65.

40. Ullah MS, Davies AJ, Halestrap AP. The plasma membrane lactate transporter MCT4, but not MCT1, is up-regulated by hypoxia through a HIF-1alpha-dependent mechanism. J Biol Chem, 2006; 281:9030-9037.

41. Wells GD, Plyley M, Thomas S, Goodman L, Duffin J. Effects of concurrent inspiratory and expiratory muscle training on respiratory and exercise performance in competitive swimmers. Eur J Appl Physiol, 2005; 94:527-540.

42. West JB. Respiratory physiology. The essentials - 9th.ed. Lippincott Williams\&Wilkins, Philadelphia, 2012

43. Woorons X, Mollard P, Pichon A, Duvallent A, Richalet JP, Lamberto C. Prolonged expiration down to residual volume leads to sever arterial hypoxemia in athletes during submaximal exercise. Resp Physiol Neurobi, 2005, 158 (1): 7582

44. Woorons X, Mollard P, Pichon A, Duvallent A, Richalet JP, Lamberto C. (2008). Effects of a 4-week training with voluntary hypoventilation carried out at low pulmonary volumes. Resp Physiol Neurobi, 2008;160 (2): 123-30.

45. Woorons $\mathrm{X}$, Bourdillon $\mathrm{N}$, Lamberto $\mathrm{C}$, Vandewalle $\mathrm{H}$, Richalet1 JP, Mollard P, Pichon A. Cardiovascular responses during hypoventilation at exercise. Int J Sports Med, 2011; 32, 438-445.

46. Woorons $\mathrm{X}$, Bourdillon $\mathrm{N}$, Vandewalle $\mathrm{H}$, Lamberto $\mathrm{C}$ Mollard P, Richalet JP, Pichon A. Exercise with hypoventilation induces lower muscle oxygenation and higher blood lactate concentration: role of hypoxia and hypercapnia. Eur J Appl Physiol, 2010; 110, 367-377.

47. Woorons X, Gamelin FX, Lamberto C, Pichon A, Richalet JP. (2014). Swimmers can train in hypoxia at sea level through voluntary hypoventilation. Resp Physiol Neurobi, 2014; 190, 33-39.

48. Woorons X, Mollard P, Pichon A, Duvallet A, Richalet JP, Lambert C. (2007). Prolonged expiration down to residual volume leads to severe arterial hypoxemia in athletes during submaximal exercise. Resp Physiol Neurobi, 2007; 158, 75-82.

49. Wylegala JA, Pendergast DR, Gosselin LE, Warkander DE, Lundgren CE. Respiratory muscle training improves swimming endurance in divers. Eur J Appl Physiol, 2007; 99:393-404.

50. Zoretic D, Grčić-Zubčević N, Zubčić K. The effects of hypercapnic-hypoxic training program on hemoglobin concentration and maximum oxygen uptake of elite swimmers. Kinesiology - International Journal of Fundamental and Applied, 2014; 46 (Suppl. 1): 40-45. 